\title{
Экономика прироАопользования
}

УДК 339.544

АМАДЗИЕВА НАИДА АБДУЛЛАЕВНА

к.э.н., старший научный сотрудник Института сочиально-экономических исследований ДФИЦ $\rho А Н$, e-mail: naida047@mail.ru

ХИЗРИЕВ АЛИХАН ШАМИЛЬЕВИЧ аспирант, Российский университет дружбы народов, e-mail: naida047@mail.ru

\section{DOI:10.26726/1812-7096-2020-06-67-74 \\ ЭКОАОГИЧЕСКИЕ И ЭКОНОМИЧЕСКИЕ АСПЕКТЫ ПРИМЕНЕНИЯ ВОЗОБНОВАЯЕМЫХ ИСТОЧНИКОВ ЭНЕРГИИ ААЯ АЕЦЕНТРААИЗОВАННОГО ЭНЕРГОСНАБЖЕНИЯ В РЕСПУБАИКЕ ААГЕСТАН}

Аннотауия. Цель работы. Постановка данного исследования определяется необходимостью поиска экологически и экономически эффективных методов освоения возобновляемых источников энергии (ВИЭ) на территории Республики Дагестан. Метод ияи методология проведения работы. Аналитический способ исследования информаиии последовательно-текстуальным методом. Результаты. Важность исследований этой проблемы обусловлена потребностью обосновать факторы и механизмы, за счет которых может быть достигнуто увеличение производства и изменение динамики потребления энергии в результате вовлечения в топливно-энергетический баланс возобновляемых источников энергии. Возобновляемые источники энергии весьма подходят для систем децентрализованного энергоснабжения. Возобновляемая энергетика особенно привлекательна для использования в сельской местности в развивающихся регионах. ВИЭ экологически приемлемы, и это является причиной их интенсивного внедрения в энергетику промышленно

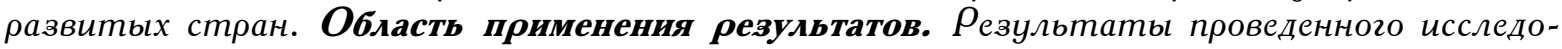
вания могут быть использованы при дальнейших разработках по изучению проблемы. Выводы. В настоящей работе предложена методика экономической оиенки эффективности ВИЭ в условиях рыночной экономики, учитывающая указанные аспекты.

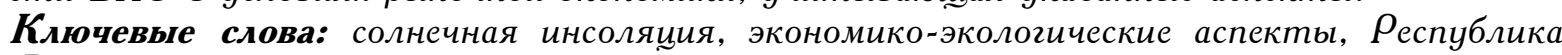
Дагестан, проекты, государственное регулирование, инвестиционный климат.

AMADZIEVA NAIDA ABDULLAYEVNA

$\rho h . D$. in Economics, senior researcher At the Institute of socio-economic research of the Russian Academy of Sciences, e-mail: naida047@mail.ru

KHIZRIEV ALIKHAN SHAMILEVICH postgraduate student, peoples ' friendship University of Russia, e-mail: naida047@mail.ru

\section{ENVIRONMENTAL AND ECONOMIC ASPECTS OF APPLICATION RENEWABLE ENERGY SOURCES FOR DECENTRALIZED ENERGY SUPPLY IN THE REPUBLIC OF DAGESTAN}

Abstract. Purpose of work. The purpose of this study is determined by the need to find environmentally and economically effective methods for developing renewable energy sources (RES) in the Republic of Dagestan. Method or methodology of the work. Analytical method for studying information sequentially-textual method. Results. The importance of research on this 
АМАДЗИЕВА Н.А., ХИЗРИЕВ А.Ш.

ЭКОЛОГИЧЕСКИЕ И ЭКОНОМИЧЕСКИЕ АСПЕКТЫ ПРИМЕНЕНИЯ ВОЗОБНОВЛЯЕМЫХ ИСТОЧНИКОВ ЭНЕРГИИ ДЛЯ ДЕЦЕНТРАЛИЗОВАННОГО ЭНЕРГОСНАБЖЕНИЯ В РЕСПУБЛИКИ ДАГЕСТАН

problem is due to the need to justify the factors and mechanisms that can be used to increase production and change the dynamics of energy consumption as a result of the involvement of renewable energy sources in the fuel and energy balance. Renewable energy sources are very suitable for decentralized energy supply systems. Renewable energy is particularly attractive for use in rural areas in developing regions. RES are environmentally acceptable, and this is the reason for their intensive implementation in the energy sector of industrialized countries. The scope of the results. The results of the study can be used for further research on the problem. Conclusions. In this paper, we propose a method of economic evaluation of RES efficiency in a market economy, taking into account these aspects.

Keywords: solar insolation, economic and environmental aspects, Republic of Dagestan, projects, state regulation, investment climate.

Введение. В настоящее время имеются все объективные предпосылки к широкому производству и внедрению оборудования, работающего на базе возобновляемых источников энергии. Это связано прежде всего с продолжающимся ростом цен на органическое топливо, большим числом рассредоточенных мелких и средних (децентрализованных) потребителей энергии в России, наличием значительной научной базы разработок для производства и внедрения оборудования, работающего на базе возобновляемых источников энергии. В Республике Дагестан использование возобновляемых источников энергии имеет особое значение.

Дагестан является самым крупным субъектом РФ по ресурсам возобновляемых источников энергии, а именно солнечной, геотермальной и гидравлической и др. Характерной особенностью Дагестана является наличие большого числа мелких потребителей энергии, удаленных от источников энергии и центров ее распределения, - это хутора, фермы и другие мелкие крестьянские хозяйства. Строительство линий электропередач или газопроводов к таким потребителям экономически невыгодно (1-5).

Поэтому нетрадиционные энергоресурсы, используемые в отдаленных районах республики для автономных энергоустановок, замещают в основном электроэнергию, а также уголь и дрова, которые дотируются из бюджета. Таким образом, использование возобновляемых источников энергии позволит значительно сократить государственные дотации.

В России и в Дагестане использование возобновляемых источников энергии обеспечивает экологическую безопасность отдельных городов и населенных пунктов со сложной экологической обстановкой.

В настоящее время темпы вовлечения возобновляемых источников энергии в топливноэнергетический баланс страны находится на неоправданно низком уровне. Это связанно с отсутствием эффективной государственной политики в этой области, неразработанностью необходимой методической базы оценки эффективности внедрения возобновляемых источников энергии, незаинтересованностью предпринимателей и неподготовленностью предприятий к серийному выпуску дорогостоящего оборудования для солнечных, ветровых, геотермальных энергоустановок.

В связи с рыночными условиями хозяйствования отрасль малой энергетики столкнулась с необходимостью разработки и внедрения новых систем управления, поскольку традиционные механизмы в данных условиях неэффективны. Подписание Россией Киотского протокола требует смещения акцентов на стратегическое управление, основными факторами которого являются: обеспечение экономической эффективности, экологической безопасности и энергетической независимости региона.

Одним из наиболее сложных вопросов в экономике энергетики, особенно в области ВИЭ, является учет фактора времени. Если раньше учет временного параметра обосновывался на понятии потерь от «замораживания» и использовании директивно и большой степени субъективно задаваемого нормативного коэффициента [6], то в нынешних условиях приведение разновременных затрат к одному расчетному времени заключается в учете инфляционных процессов и процентных ставок на капитал. При этом термин «приведенные затраты» может быть использован в смысле их дисконтирования. Достаточно сказать, что в настоящее время при технико-экономическом обосновании эффективности альтернативных источников энергии 
такие важнейшие показатели, как темпы инфляции и роста цен на органическое топливо, как правило, не используются, хотя эти факторы в первую очередь существенно влияют на эффективность ВИЭ. Расчеты, проводимые для стационарных условий текущего периода, приводят к ложному выводу об неэффективности ВИЭ.

Кроме опережающих темпов роста цен на органическое топливо, фактором, обуславливающим повышение конкурентоспособности альтернативных источников, особенно гелиосистем теплоснабжения, являются незначительные сроки их строительства, что связано с меньшими инфляционными и кредитными потерями.

При выборе критериев и методики расчета эффективности ВИЭ необходимо учесть не только направление инвестиций (выпуск соответствующего оборудования различными производителями или внедрение их у конкретных потребителей), но и источники финансирования (государственные или частные инвестиции).

В настоящей работе предложена методика экономической оценки эффективности ВИЭ в условиях рыночной экономики, учитывающая указанные аспекты.

Говоря об экономике использования нетрадиционных энергоресурсов, необходимо отдельно рассмотреть два различных, хотя и взаимосвязанных вопроса: производство энергоустановок, работающих на базе ВИЭ, и внедрение их в различных отраслях хозяйства.

C точки зрения производителя основным критерием является норма прибыли (доходности), определяемая по известной формуле

$$
p_{n}=\sum_{t=1}^{T} \Pi_{t}(1+p)^{-t} / \sum_{t=1}^{T} K_{t}(1+p)^{-t}
$$

где $\Pi_{\mathrm{t}}-$ величина эффекта в $\mathrm{t}-$ й год расчетного периода;

$K_{t}$ - величина капитальных затрат, вносимых в $t$-й год;

$T$ - продолжительность расчетного периода;

$p$ - коэффициент дисконтирования.

Коэффициент дисконтирования фактически носит смысл процентной ставки на капитал и обычно применяется равной норме процента от долговых обязательств. Некоторые исследователи в расчетах $p$ принимают равным уровню инфляции.

Величина эффекта определяется как величина дохода от реализации продукции за вычетом капиталовложений и годовых издержек:

$\Pi_{t}=Д_{t}-K_{t}-И_{t}$

Для оценки эффективности наряду с нормой прибыли используется также так называемая внутренняя норма рентабельности $p_{p}$, определяемая из решения уравнения:

$$
\sum_{t=1}^{T}\left(д_{t}-K_{t}-H_{t}\right)\left(1+p_{p}\right)=0 .
$$

Этот коэффициент показывает максимально допустимый процент кредита, при котором данный проект может быть инвестирован.

Однако такой подход делает невыгодным (с точки зрения предпринимателя) проекты перспективного характера с долговременными капиталовложениями даже при очевидности их прогрессивного характера для развития энергетики [18]. Поэтому при государственном финансировании перспективных проектов по организации производства энергооборудования для ВИЭ необходимо законодательно ввести критерий, объективно отражающий структуру расходов и доходов. Таким критерием является отношение дисконтированных величин доходов и затрат:

$$
p_{g}=\bar{д} /(\bar{\kappa}+\bar{U})
$$

где

$$
\bar{Д}=\sum_{t=1}^{T} Д_{t}(1+p)^{-t} ; \quad \bar{K}=\sum_{t=1}^{T} K_{t}(1+p)^{-t} ; \quad \bar{И}=\sum_{t=1}^{T} U_{t}(1+p)^{-t} .
$$

Необходимо заметить, что в ряде стран, в том числе в США (для гидроэнергетики), этот критерий широко используется. Для производств с малой капиталоемкостью, т. е. при малых 
значениях $\bar{K}, \bar{H}$, норма прибыли может изменяться в широких пределах при незначительном изменении $p_{g}$, что говорит о большой стабильности и объективности.

Потребитель, внедряющий у себя эти энергоустановки, заинтересован в экономическом эффекте, достигаемом за счет замещения ими энергии традиционных источников.

В настоящее время практически отсутствует отработанная методическая база техникоэкономического обоснования выбора ВИЭ, хотя имеются попытки решать некоторые частные задачи для отдельных видов альтернативных источников и схем их использования [17]. Это связано в первую очередь с различным природным характером энергетических потоков ВИЭ и тем, что за незначительным исключением они требуют наличия в качестве резерва традиционного источника энергии.

Рассмотрим более подробно вопросы выбора экономических критериев и формирования затрат при строительстве и эксплуатации энергообъектов, работающих на базе ВИЭ. При этом будем исходить из следующих соображений [7]:

1. Общая потребность в энергии $Q$ и мощности $P$ покрывается как за счет традиционного источника (ТИЭ), так и установки, использующей НВИЭ (НИЭ). Обозначим их $Q_{m и э}, P_{m и э} u$ $Q_{\text {ниэ},} P_{\text {ниэ }}$ соответственно. При этом коэффициенты замещения по энергии и мощности равны:

$$
\begin{aligned}
& K_{a}=Q_{\text {тиэ }} / Q ; \\
& K_{p}=P_{\text {ниэ }} / P . \\
& Q_{\text {ниэ }}+Q_{\text {тиэ }}=Q ; \\
& P_{\text {ниэ }}+P_{\text {тиэ }}{ }^{3} P .
\end{aligned}
$$

2. В общем случае предусмотрена аккумулирующая установка (АУ), позволяющая сглаживать несоответствие между графиком потребления энергии и поступлением ее от ВИЭ.

3. В качестве расчетного периода $T$ примем срок службы ВИЭ. Корректность такого допущения объясняется следующим. Если в качестве ТИЭ используется автономная система энергоснабжения, то срок службы последней, как правило, соизмерим со сроком службы НИЭ. Если же в качестве ТИЭ выступает централизованная система энергоснабжения, то условия эксплуатации в течение расчетного периода практически не меняются.

4. Экономическая эффективность ВИЭ в решающей степени зависит от уровня цен на органическое топливо, следовательно, и стоимости вырабатываемой ТИЭ энергии. При этом темпы их роста в большинстве случаев опережают общие темпы инфляции. Поэтому в общем случае в расчетах необходимо учесть фактор опережающего роста цен на топливо $[8,9]$.

В качестве основной оценки эффективности используется ВИЭ, должен быть принят критерий минимума дисконтированных затрат или максимума экономического эффекта за расчетный период, необходимых для обеспечения потребности в энергии $Q$.

В первую очередь также необходимо реализовать альтернативные варианты решения экологических проблем, т. е. варианты, непосредственно не связанные с природоэксплуатирующей и природоохранной деятельностью. Прямые природоохранные мероприятия, меры по охране окружающей среды должны реализовываться лишь при невозможности решения экологических проблем при данном технологическом уровне на основе альтернативных вариантов или малоотходных и безотходных технологий.

Децентрализованное энергоснабжение, в особенности автономное, целесообразно базировать на местных источниках энергии. Это особенно существенно для удаленных регионов, поскольку доставка туда обычного топлива связана с существенными затратами и не всегда надежна. Те или иные возобновляемые источники энергии (ВИЭ) имеются практически в любом месте - это солнечная энергия, энергия ветра, энергия биомассы (включая органические отходы). В некоторых случаях доступна волновая энергия, энергия, связанная с разностью температур в океане, приливная и геотермальная энергия. Для горячего водоснабжения и отопления могут использоваться источники низкопотенциального тепла в комбинации с тепловыми насосами, при этом одним из наиболее приемлемых низкопотенциальных источников является грунт, который одновременно может служить и аккумулятором тепла или холода.

Одним из факторов, от которых зависит целесообразность использования ВИЭ, являются их экологические характеристики. Малые по мощности установки децентрализованного энер- 
госнабжения располагаются обычно в непосредственной близости от населенных пунктов, и поэтому их экологическая совместимость является предметом пристального рассмотрения. С точки зрения экономики, применение солнечной энергии - и для получения низкопотенциального тепла, и для производства электроэнергии с помощью фотоэлектропреобразователей может считаться приемлемым. Применение ветровой энергии в большом числе случаев сопровождается некоторыми нежелательными последствиями: работающие ветровые турбины производят шум, возникает опасность для птиц, высокие башни ветровых установок нарушают ландшафт. Для выяснения степени этих нежелательных воздействий проводятся специальные исследования. Энергетическое использование биомассы осуществляется различными методами. Они включают непосредственное сжигание, термохимическую газификацию, производство биогаза из сельскохозяйственных отходов, производство этанола из сахарного тростника или кукурузы. Поскольку биомасса состоит в основном из углеводов, любое использование ее приводит к образованию диоксида углерода. Если биомасса (древесина и отходы лесной и деревоперерабатывающей промышленности) используется так, что на месте использованных растений выращиваются новые, то в первом приближении достигается близкая к нулевой суммарная эмиссия СОг. Извлечение энергии из морей и океанов также сопряжено с некоторыми возможными экологическими осложнениями. В последнее время в разных странах мира проводится большое число исследований для выяснения возможных отрицательных воздействий ВИЭ на окружающую среду и выработки мер по их устранению [10-12].

Децентрализованные энергетические установки, будь то присоединенные к сети или автономные, в большинстве случаев располагаются в непосредственной близости к потребителям. В отличие от систем централизованного энергоснабжения единичная мощность децентрализованных агрегатов сравнительно невелика (лежит в пределах от десятков кВт до нескольких МВт). Эти агрегаты целесообразно базировать на местных источниках энергии, и в частности на ВИЭ. В любом регионе имеется тот или иной возобновляемый источник энергии, и в подавляющем числе случаев такие источники достаточно экологически чисты.

Наибольший потенциал имеет солнечная энергия, однако не во всех регионах целесообразно ее использовать, поскольку годовое поступление солнечной энергии резко убывает по мере увеличения широты местности.

Ветровая энергия имеется практически повсеместно. Поскольку мощность ветрового потока пропорциональна кубу скорости, экономически эффективное использование этого источника энергии оправдано лишь там, где среднегодовые скорости ветра не ниже 5 м/с. Имеются некоторые вредные воздействия на окружающую среду, которые необходимо учитывать.

Следует также учесть, что оба упомянутых источника энергии не постоянны во времени. Поэтому чтобы автономная энергоустановка могла удовлетворить потребителя, необходимо наряду с солнечной или ветровой установкой предусматривать резервное устройство, например аккумуляторную батарею (для малых установок) или дизель-генератор. Для систем с ВИЭ, присоединенных к сети, резервная установка может не понадобиться, поскольку предполагается, что сеть сможет сгладить неравномерность поступления первичной энергии от ВИЭ. Однако для того, чтобы сеть могла выполнять эту роль, мощность установок с ВИЭ не должна превышать 10-20\% от емкости сети.

Более постоянным источником энергии и широко распространенным является биомасса, как первичная, т. е. растущие растения на суше или водоросли в воде, так и вторичная - всевозможные сельскохозяйственные, промышленные и муниципальные отходы. Имеются экологические проблемы, связанные с использованием первичной или вторичной биомассы.

Малые реки могут рассматриваться как потенциально значимый источник энергии. Но при этом надо иметь в виду, что создание водохранилищ, сооружение плотин могут иметь нежелательные экологические последствия.

Для целей отопления, особенно в северных регионах, можно использовать низкопотенциальные источники тепла, поднимая температуру этого тепла с помощью тепловых насосов. В ряде случаев это может быть целесообразным мероприятием, несмотря на то, что ему могут сопутствовать некоторые экологические осложнения.

Использование геотермальной энергии для производства электроэнергии ограничено регионами, где достаточно горячие геотермальные флюиды находятся на небольших глубинах. 
Примером таких регионов являются районы, расположенные по побережью Каспийского моря. Геотермальные месторождения, приемлемые для производства электроэнергии, встречаются не слишком часто. Напротив, низко- и среднетемпературные термальные воды широко распространены и могут быть использованы либо непосредственно, либо в сочетании с тепловыми насосами, при условии что экологические соображения будут приняты в расчет.

Децентрализованное энергоснабжение на базе ВИЭ должно сопоставляться с традиционными источниками энергии не только с учетом экономических критериев, но и используя экологические соображения [13-15]

\section{Солнечная энергия}

Солнечная энергия широко используется для горячего водоснабжения и отопления. Наиболее распространены установки для индивидуальных домов, которые представляют собой плоский солнечный коллектор площадью в 1-2 м² и бак-аккумулятор емкостью в 100-200 л. В некоторых случаях применяется поле коллекторов, обеспечивающее централизованное теплоснабжение небольших поселений. Это оборудование не причиняет вреда окружающей среде, поскольку рабочим теплоносителем в этих установках в большинстве случаев является чистая вода. В северных странах такие установки работают на антифризе, утечки которого могут наносить некоторый ущерб. Минус в том, что стеклянное покрытие солнечных коллекторов, отражая солнечные лучи, может ослеплять пилотов пролетающих самолетов. Во избежание этих возможных осложнений рекомендуется, особенно для крупных установок, делать стеклянные покрытия коллекторов из ребристого стекла.

Производство электроэнергии за счет солнечной радиации сегодня в основном базируется на использовании фотоэлектропреобразователей (ФЭП). Продолжаются исследовательские и опытные работы, направленные на создание солнечных электростанций (СЭС), использующих термодинамический цикл преобразования энергии. Построены сравнительно крупные установки, использующие этот принцип. Наиболее известны установки, построенные международной компанией «Луз» в Калифорнии. Суммарная мощность этих СЭС, использующих параболоцилиндрические концентраторы, составляет 354 МВт. Создаются также так называемые башенные СЭС, в которых солнечная радиация концентрируется полем зеркал-гелиостатов и нагревает ресивер, установленный на верху достаточно высокой башни. Наиболее известна опытная башенная СЭС SolarOne мощностью 10 МВт, построенная в Калифорнии, и с момента еe сооружения уже дважды реконструированная (SolarTwo). Создаются также установки малой мощности с параболическими концентраторами и двигателями Стирлинга, устанавливаемыми в фокусе. Однако все эти СЭС (за исключением созданных компанией «Луз»), несмотря на то, что их экономика лучше, чем у ФЭП, являются, по существу, только демонстрационными или опытными. Следует отметить, что промышленно эксплуатируемые в США установки «Луз» не являются полностью «чистыми», поскольку они работают по гибридной схеме. Это означает, что наряду с солнечной энергией они используют для продления работы СЭС за пределы светового дня некоторое количество природного газа. Следовательно, эти СЭС эмитируют некоторое количество $\mathrm{C}_{2}$. Продление работы СЭС за пределы светового дня, а также компенсация переменности поступления солнечной радиации могут быть достигнуты и путем использования аккумуляторов тепла, как это сделано на СЭС SolarTwo. Такой аккумулятор использует либо физическое тепло какого-либо рабочего тела, либо скрытую теплоту фазового перехода (чаще всего плавления-затвердевания) какой-нибудь соли, например селитры. Утечки такого вещества могут быть опасны для окружающей среды.

Для сельских односемейных домов в развивающихся регионах сегодня рекомендованы модули ФЭП мощностью 50-300 Вт. Собственно, модули ФЭП не оказывают отрицательного воздействия на окружающую среду, однако при их производстве используются вещества и процессы, вредные для здоровья людей. Из-за того, что поступление солнечной радиации непостоянно во времени, для непрерывного электроснабжения при использовании ФЭП необходимо иметь дублирующую установку или аккумулятор, в частности наиболее дешевый свинцово-кислотный аккумулятор. Эти аккумуляторы могут являться источником экологических загрязнений. Средний срок жизни аккумуляторной батареи составляет около трех лет, тогда как время жизни ФЭП около 20 лет. Это означает частую смену аккумуляторов с соответствующим потоком свинца (аккумулятор емкостью 80 А-ч содержит около 18 кг свинца). 
Захоронение или переработка этого свинца может наносить вред окружающей среде. Для преодоления этого недостатка необходима разработка новых устройств для аккумулирования электроэнергии. Системы с ФЭП, присоединенные к сети, не нуждаются в аккумуляторах и лишены этого недостатка $[16,17]$.

Результаты. Таким образом, можно сделать вывод, что Республика Дагестан обладает всем необходимым, чтобы реализовать альтернативные варианты решения экологических проблем, т. е. варианты, непосредственно не связанные с природоэксплуатирующей и природоохранной деятельностью. Использование солнечных тепловых установок для отопления и горячего водоснабжения жилых индивидуальных домов является актуальным и перспективным направлением в энергетике южных регионов России.

Комбинирование солнечных коллекторов с тепловыми насосами и грунтовыми аккумуляторами в техническом плане реализуемо, а в экономическом плане намного эффективнее, чем отдельное использование коллекторов.

Выводы. Результаты НИР могут быть использованы при создании эффективной комбинированной энергетической установки для теплоснабжения жилых домов сельского типа в республиках Северного Кавказа, в первую очередь Дагестана.

Использование солнечных установок с тепловыми насосами и грунтовыми аккумуляторами позволит решить социально-экономические, энергетические и экологические проблемы сельских районов Республики Дагестан.

\section{Литература}

1. Алхасов А. Б., Дибиров М. Г. Дибирова М. М. Перспективы использования солнечной энергии в Дагестане // Материаль конферениии «Актуальные проблемы освоения возобновляемых энергоресурсов». Махачкала, 2012. - С. 324.

2. Амадзиева Н. А. Потенциал и проблемы использования возобновляемых источников энергии в Республике Дагестан и СКФО // Региональные проблемы преобразования экономики. - 2015. - № 3. - С. 24-30. 3. Амадзиева Н. А., Хизриев А. Ш. Возобновляемая энергетика как один из факторов энергосбережения на сельских территориях Республики Дагестан // Региональные проблемы преобразования экономики. 2016. - № 2. - C. 90-96.

4. Амадзиева Н. А., Инвестииионная поддержка и экономическое стимулирование развития солнечных источников энергии в Дагестане // Региональные проблемы преобразования экономики. - 2017. - № 2 (76). - C. 4-9.

5. Бамирова А. А., Гимбатов Г. М. Экологические инноваиии в сельском хозяйстве: место и роль в системе инноваиий // Региональные проблемы преобразования экономики. - 2015. - № 6 (56). - C. 11-15.

б. Деневизюк Д. А., Омарова К. А., Елисеева Е. М. Состояние, проблемы и направления развития соииальной инфраструктуры сельских поселений Республики Дагестан // Региональные проблемы преобразования экономики. - 2012. - № 3 (33). - С. 295-304.

7. Дибиров М. Г., Дибирова М. М. Состояние использования возобновляемых источников энергии в Дагестане // Материалы научной сессии «Возобновляемая энергетика: проблемы и перспективы». - Махачкала, 2014. - С. 35 .

8. Дибиров М. Г., Амадзиева Н. А., Дибирова М. М. Методические основы оиенки эффективности солнечных тепловых установок // Региональные проблемы преобразования экономики. - 2018. - № 6. - С. $12-20$.

9. Дибиров М. Г., Амадзиев А. М., Дибирова М. М. Новые материалы для солнечных коллекторов // Пищевая промышленность. - 2008. - № 11.

10. Дибиров М. Г., Шахбанов А. Б., Гаджиев Г. А., Дибирова М. М. Дома с солнечным теплоснабжением в Дагестане // Материалы V Международной конференции «Возобновляемая энергетика: проблемы и перспективы», выпуск 6. - Махачкала, 2017. - С. 262.

11. Магомедова Н. А. Концепџия развития возобновляемой энергетики Республики Дагестан как составная часть инновачионной экономической политики // Региональная экономика: теория и практика. -2010 . - № 38. - C. 20-25.

12. Магомедова Н. А. Стратегия привлечения возобновляемых энергоресурсов в развитие потенциала энергетики как составная часть инновачионной политики региона // Региональные проблемы преобразования экономики. - № 1. - 2011. - С. 123-129.

13. Селиванов Н. П., Мелуа А. И., Зоколей С. В. и др. Энергоэффективные здания. Изд. «Стройиздат». M., 1988 .

14. Сибикин Ю. Д. Нетрадииионные и возобновляемые источники энергии: Учебное пособие/ 2-е издание. - М.: КНОРУС, 2012. -240 c.

15. Попель О. С. Фрид С. Е. Об использовании солнечных водонагревателей в климатических условиях средней полосы России // Проблемы энергосбережения. - № 7. - 2001.

16. Петросяни В. З., Бамирова А. А. Сельское хозяйство и природная среда: проблемы экологизации развития // Проблемы развития АПК региона. - 2012. - Т. 11. - № 3 (11). - С. 175-179.

17. Фортов В. Е., Попель О. С. Энергетика в современном мире. - Долгопрудный: ИД «Интеллект», 2011. 


\section{АМАДЗИевА Н.А., ХИзРИЕВ А.Ш.}

ЭКОЛОГИЧЕСКИЕ И ЭКОНОМИЧЕСКИЕ АСПЕКТЫ ПРИМЕНЕНИЯ ВОЗОБНОВЛЯЕМЫХ ИСТОЧНИКОВ ЭНЕРГИИ ДЛЯ ДЕЦЕНТРАЛИЗОВАННОГО ЭНЕРГОСНАБЖЕНИЯ В РЕСПУБЛИКИ ДАГЕСТАН

18. Фрид С. Е., Коломиеи Ю. Г. Эффективность и перспективы использования различных систем солнечного нагрева воды в климатических условиях Российской Федерации // Теплотехника, 2011. - № 11. 19. Dahmann J., Baldwin K. Understanding the Current State of US Defense Systems of Systems and the Implications for Systems Engineering // IEEE Systems Conference. Montreal, 2008.

\section{References:}

1. Alhasov A. B., Dibirov M. G. Dibirova M. M. Perspektivy ispol'zovaniya solnechnoj energii v Dagestane // Materialy konferencii "Aktual'nye problemy osvoeniya vozobnovlyaemyh energoresursov». - Mahachkala, 2012. - S. 324

2. Amadzieva N. A. Potencial i problemy ispol'zovaniya vozobnovlyaemyh istochnikov energii v Respublike Dagestan i SKFO // Regional'nye problemy preobrazovaniya ekonomiki. - 2015. - № 3. - S. 24-30.

3. Amadzieva N. A., Hizriev A. SH. Vozobnovlyaemaya energetika kak odin iz faktorov energosberezheniya na sel'skih territoriyah Respubliki Dagestan // Regional'nye problemy preobrazovaniya ekonomiki. - 2016. - № 2. - S. 90-96.

4. Amadzieva N. A., Investicionnaya podderzhka i ekonomicheskoe stimulirovanie razvitiya solnechnyh istochnikov energii v Dagestane // Regional'nye problemy preobrazovaniya ekonomiki. - 2017. - № 2 (76). - S. 49.

5. Bashirova A. A., Gimbatov G. M. Ekologicheskie innovacii v sel'skom hozyajstve: mesto i rol'v sisteme innovacij // Regional'nye problemy preobrazovaniya ekonomiki. - 2015. - № 6 (56). - S. 11-15.

6. Denevizyuk D. A., Omarova K. A., Eliseeva E. M. Sostoyanie, problemy i napravleniya razvitiya social'noj infrastruktury sel'skih poselenij Respubliki Dagestan // Regional'nye problemy preobrazovaniya ekonomiki. 2012. - № 3 (33). - S. 295-304.

7. Dibirov M. G., Dibirova M. M. Sostoyanie ispol'zovaniya vozobnovlyaemyh istochnikov energii v Dagestane // Materialy nauchnoj sessii «Vozobnovlyaemaya energetika: problemy i perspektivy». - Mahachkala, 2014. - S. 35 .

8. Dibirov M. G., Amadzieva N. A., Dibirova M. M. Metodicheskie osnovy ocenki effektivnosti solnechnyh teplovyh ustanovok // Regional'nye problemy preobrazovaniya ekonomiki. - 2018. - № 6. - S. 12-20.

9. Dibirov M. G., Amadziev A. M., Dibirova M. M. Novye materialy dlya solnechnyh kollektorov // Pishchevaya promyshlennost'. - 2008. - № 11 .

10. Dibirov M. G., SHahbanov A. B., Gadzhiev G. A., Dibirova M. M. Doma s solnechnym teplosnabzheniem v Dagestane // Materialy V Mezhdunarodnoj konferencii «Vozobnovlyaemaya energetika: problemy i perspektivy», vypusk 6. - Mahachkala, 2017. - S. 262.

11. Magomedova N. A. Koncepciya razvitiya vozobnovlyaemoj energetiki Respubliki Dagestan kak sostavnaya chast' innovacionnoj ekonomicheskoj politiki // Regional'naya ekonomika: teoriya i praktika. - 2010. - № 38. S. 20-25.

12. Magomedova N. A. Strategiya privlecheniya vozobnovlyaemyh energoresursov $v$ razvitie potenciala energetiki kak sostavnaya chast' innovacionnoj politiki regiona // Regional'nye problemy preobrazovaniya ekonomiki. - № 1. - 2011. - S. 123-129.

13. Selivanov N. P., Melua A. I., Zokolej S. V. i dr. Energoeffektivnye zdaniya. Izd. "Strojizdat». - M., 1988.

14. Sibikin YU. D. Netradicionnye $i$ vozobnovlyaemye istochniki energii: Uchebnoe posobiel 2 -e izdanie. - M.: KNORUS, 2012. - $240 \mathrm{~s}$.

15. Popel' O. S. Frid S. E. Ob ispol'zovanii solnechnyh vodonagrevatelej v klimaticheskih usloviyah srednej polosy Rossii // Problemy energosberezheniya. - № 7. - 2001.

16. Petrosyanc V. Z., Bashirova A. A. Sel'skoe hozyajstvo i prirodnaya sreda: problemy ekologizacii razvitiya // Problemy razvitiya APK regiona. - 2012. - T. 11. - № 3 (11). - S. 175-179.

17. Fortov V. E., Popel' O. S. Energetika v sovremennom mire. -Dolgoprudnyj: ID «Intellekt», 2011.

18. Frid S. E., Kolomiec YU. G. Effektivnost' i perspektivy ispol'zovaniya razlichnyh sistem solnechnogo nagreva vody v klimaticheskih usloviyah Rossijskoj Federacii // Teplotekhnika, 2011. - № 11 .

19. Dahmann J., Baldwin K. Understanding the Current State of US Defense Systems of Systems and the Implications for Systems Engineering // IEEE Systems Conference. Montreal, 2008. 